\title{
N-Acyl Homoserine Lactone-Mediated Quorum Sensing System Inhibition of Phenolic Strawberry Extract
}

\author{
Sedef İlk* \\ Department of Immunology, Faculty of Medicine, Niğde Ömer Halisdemir University, 51240 Niğde, Turkey \\ A R T I C LE INF O

\section{Research Article} \\ Received 05 July 2018 \\ Accepted 10 October 2018 \\ Keywords: \\ Fragaria $\times$ ananassa \\ Phenolic extracts \\ Antioxidant activity \\ Quorum sensing inhibition \\ Antimicrobial activity \\ *Corresponding Author: \\ E-mail: sedefilk@ohu.edu.tr

\begin{abstract}
Phenolic compounds which have many bioactivities such as antioxidant, antimicrobial and also inhibition of quorum sensing-regulated violacein pigment production properties are one of the plant secondary metabolites. The objective of this study was to determine the antioxidant, antimicrobial activity and the inhibition of quorum sensing (QSI) activity by the phenolic extract obtained from strawberry fruits (Fragaria $\times$ ananassa cv. 'Rubygem'). The phenolic content of extract was determined as $3089 \mu \mathrm{g} \mathrm{GAE} \mathrm{g} \mathrm{fw}{ }^{-1}$. The antioxidant activity determined through the $\mathrm{ABTS}^{+}$and FRAP method was 28.4 and $26.2 \mathrm{mmol} \mathrm{TE} \mathrm{L}^{-1}$ respectively. The phenolic extract was able to inhibit all the evaluated bacteria by the disc diffusion assay in the range of $3.12-18.36 \mathrm{~mm}$ and could inhibit the quorum sensing phenomena in bacteria. The strawberry phenolic extract exhibited high antioxidant capacity, antimicrobial and anti-quorum sensing properties. To our knowledge, this is the first report on the quorum sensing inhibition activity of strawberry fruit extract. The discovery of non-toxic novel compounds within antibacterial and QSI activity could lead to the development of antimicrobial therapeutic agents that can be alternative and complementary treatments against antibiotic resistant bacterial pathogens.
\end{abstract} \\ A B S T R A C T
}

DOI: https://doi.org/10.24925/turjaf.v6i12.1789-1794.2100

\section{Introduction}

Bacteria have gained resistant to conventional antibiotics day by day which leads to deliver promising 'discovery of new drug' (Andrade et al., 2014; Borges et al., 2013; Andersson and Hughes, 2010; Projan and Youngman, 2002). The use of compounds which inhibit bacterial communication in biofilms provides a direct approach to this problem (O'Loughlin et al., 2013). The bacterial communication is regulated by a cell densitydependent chemical process called as "quorum sensing" (QS). In QS process, bacteria (gram-negative) release signal molecules by recognition of receptor proteins that control the expression of a particular set of genes and regulate varied properties which increase to a certain threshold concentration in the environment (Singh et al., 2012). QS targeting could be a promising strategy to control pathogenic bacteria while this mechanism is responsible for bacterial virulence induction (Jorge et al., 2012). The prevention of bacterial infection based on inhibition of bacterial communication system by natural products has emerged in recent years. Therefore, the current research for new antimicrobials is aimed to determine natural and non-toxic QS inhibitors that can be applied for bacterial infection treatments in humans (Hentzer and Givskov, 2003). Several plants and their fruits which have bioactive compounds could be

developed as functional nutrition due to their ability to inhibit bacterial communication and prevent infection. The inhibition of QS mechanisms by natural products have been not identified completely yet but recent researches have been clarified some strategies included that the synthesis inhibition and/or the enzymatic degradation of auto inducer signal molecules, prevention of signal molecules secretion and receptor antagonism (McCarthy and O'Gara, 2015).

Phenolic compounds are secondary metabolites affect against phytopathogens in fruits and vegetables and are also capable of inhibiting the production of signal molecules and growth of microorganisms according to their concentration (Tiveron et al., 2012). The dietary phytochemicals have great attention for managing QS and infectious diseases recently (Martins et al., 2015). These phytochemicals are rarely associated with any side-effects as seen in many antibiotic regimens and generally recognized as safe (GRAS), because they are derived from dietary natural sources (Cowan, 1999). From recent several studies it was recognized that these phytochemicals could be used to a new antimicrobial therapeutics that overcome antibiotic resistance (Pinho et al., 2014). The fruits from the family Rosaceae have a great capacity of secondary metabolites such as 
flavonoids, phenolics, alkaloids, quinones, polyacetylenes and terpenoids (Puupponen-Pimia et al., 2005). Although extensive works have been done on the antimicrobial properties of phenolic compounds of strawberry fruits, it is interesting that the literature about the dietary polyphenolics of strawberry as potential of QSI is very limited (Martins et al., 2015). 'Rubygem' is an early spring cultivar grown in most strawberry-growing areas (Herrington et al., 2007). The fruit is rich in anthocyanins content that presents its biological and therapeutic activity (Santoni et al., 2015; Campbell et al., 2015). Results obtained from strawberry extract provided high phenolic content, antioxidant, antimicrobial and QSI activities. Thus, the present study was performed to evaluate some bioactivities of phenolic compounds such as their antioxidant, antibacterial and QSI properties of strawberry cultivar 'Rubygem' (Figure 1).

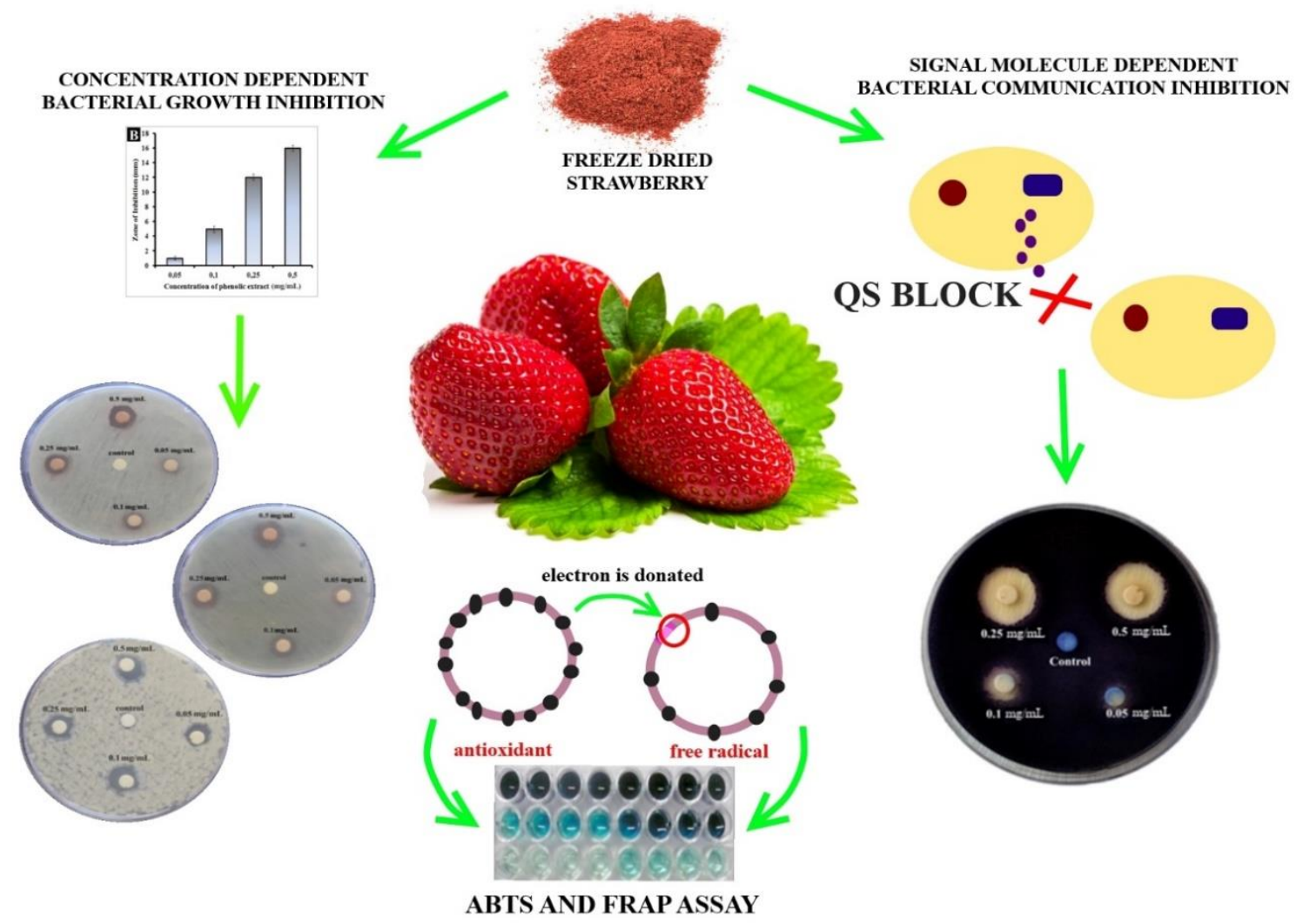

Figure 1 Schematic illustration of the objective of the study: determination of total phenolic content, antioxidant capacity, antimicrobial and quorum sensing inhibition properties of strawberry fruits (Fragaria $\times$ ananassa $\mathrm{cv}$.

'Rubygem') phenolic extract.

\section{Materials and Methods}

\section{Phenolic Extract Preparation}

Strawberry fruits cv. 'Rubygem' were harvested from Silifke district of Mersin province, Turkey, frozen immediately and stored at $-20^{\circ} \mathrm{C}$ until analyse. Samples were defrosted at room temperature and homogenized in a blender (WARING, 8010EG). The slurry was homogenized and dried into powder by using lyophilization. The seeds in the dry samples were removed. The total phenolic content of the extracts was determined by the Folin-Ciocalteu assay (Singleton and Rossi, 1965) and expressed as $\mu \mathrm{g}$ of gallic acid equivalent per $g$ fresh weight basis $\left(\mu \mathrm{g} \mathrm{GAE} \mathrm{fw}^{-1}\right)$. The phenolic extract term used in this study has no relation to the solvent system used to obtain the extract.

\section{Total Phenolic Content Determination}

The Folin-Ciocalteu assay was used for the determination of the total phenolic content of the extracts. Briefly; Folin-Ciocalteu reagent $(1 \mathrm{~mL})$ and obtained extract solution $(1 \mathrm{~mL})$ were mixed thoroughly (Singleton and Rossi, 1965). After 8 min., $7 \% \mathrm{Na}_{2} \mathrm{CO}_{3}$ (10 mL) was added and then the mixture was kept at room temperature. The absorbance at $750 \mathrm{~nm}$ was measured by UV/Vis spectrophotometer (PG Instruments, T60U UV-Visible, UK). The total phenolic concentration was calculated as $\mu \mathrm{g}$ of gallic acid equivalent by using an equation obtained from gallic acid calibration curve. The total phenolic compound assay was carried out in triplicate.

\section{ABTS Radical Scavenging Assay}

For the ABTS (2,2-azino-bis-3-ethylbenzothiazoline6-sulfonic acid) assay, firstly ABTS was dissolved in buffer of acetate and mixed with potassium persulfate according to method with some modifications (Özgen et al., 2006). Then, the obtained solution was diluted in sodium acetate buffer $(20 \mathrm{mM}, \mathrm{pH} 4.5)$. Finally, the ABTS $^{++}$solution $(2.97 \mathrm{~mL})$ and fruit extract $(30 \mu \mathrm{L})$ were mixed and kept for $10 \mathrm{~min}$ and the absorbance was determined at $734 \mathrm{~nm}$. 


\section{FRAP Assay}

The FRAP assay was carried out by three aqueous stock solutions containing $0.1 \mathrm{~mol} / \mathrm{L}$ acetate buffer $(\mathrm{pH}$ 3.6), $10 \mathrm{mmol} \mathrm{L}^{-1}$ TPTZ [2,4,6-tris(2-pyridyl)-1,3,5triazine] acidified with hydrochloric acid and ferric chloride (20 mmol L-1) (Benzie and Strain, 1996). These solutions were prepared $(10: 1: 1, v / v / v)$ as the FRAP reagent to analysis. The FRAP reagent $(2.97 \mathrm{~mL})$ and phenolic extract $(30 \mu \mathrm{L})$ were mixed. After the incubation (10 min.), the reaction mixture's absorbance was determined at $593 \mathrm{~nm}$ using UV/Vis spectrophotometer. Each assay was done in triplicate.

\section{Antimicrobial Activity}

The antimicrobial activity of the strawberry phenolic extract within different concentrations was determined by disc diffusion method. The tests were performed against human pathogens gram negative bacteria Escherichia coli ATCC 25922, Proteus vulgaris ATCC 6380, Salmonella spp. (Laboratory stock) and the gram positives Staphylococcus aureus ATCC 25923, Streptococcus mutans ATCC 25175 and Bacillus subtilis ATCC 21332. All the strains were sub-cultured before use. For the disc diffusion assay, the procedure described by the CLSI disc-diffusion method was followed (Yağız et al., 2017). To adjust the turbidity of microorganisms, 0.5 McFarland standard was used as a reference. The fruit extract powder was dissolved in ethanol:water $(5: 95, \mathrm{v} / \mathrm{v})$ solvent. Microorganism suspensions $(100 \mu \mathrm{L})$ were inoculated $\left(1 \times 10^{8} \mathrm{CFU} \mathrm{mL} \mathrm{m}^{-1}\right)$ onto Müller-Hinton medium. Filter discs (diameter:6 $\mathrm{mm}$ ) were placed on inoculated petri plate and $20 \mu \mathrm{L}$ of fruit extract solution was added onto each filter disc. Plates were incubated at $37^{\circ} \mathrm{C}$ for $24 \mathrm{~h}$. Only ethanol:water $(5: 95, v / v)$ solvent containing discs were used as a negative control. After the incubation, the inhibition zone's diameter was calculated. All tests were carried out triplicate and mean values were calculated.

\section{Quorum Sensing Inhibition Activity}

The Chromobacterium violaceum (C. violaceum) ATCC 12472 biomonitor strain was employed to evaluate QSI properties of strawberry phenolic extract. The $C$. violaceum suspension was recovered by overnight incubation $\left(30^{\circ} \mathrm{C}\right)$ in Luria-Bertani (LB) broth.

\section{Quorum Sensing Inhibition in C. violaceum}

Initially, the suspension of C. violaceum ATCC 12472 was standardized to an $\mathrm{OD}_{620 \mathrm{~nm}}$ of 1 and was seeded on the LB agar plates. Sterile discs (diameter: $6 \mathrm{~mm}$ ) impregnated with the phenolic extract solution $(20 \mu \mathrm{L})$ in different concentrations $\left(0.5,0.25,0.1,0.05 \mathrm{mg} \mathrm{mL}^{-1}\right)$ were placed over the plates and incubated $\left(30^{\circ} \mathrm{C}, 24 \mathrm{~h}\right)$. Discs with distilled sterilized ethanol:water $(5: 95, v / v)$ were used as negative control. The quorum sensing inhibitory activity in $C$. violaceum was determined by a turbid halo formation that presented no pigment production by bacterial growth around the well on a purple background on the plate. The QSI, measured by the inhibition of violacein pigment, was calculated by subtracting the diameter of bacterial growth inhibition $\left(d_{1}\right)$ from the total diameter $\left(d_{2}\right)\left(Q S I=d_{2}-d_{1}\right)$. Diameter 1 $\left(d_{1}\right)$ : the inhibition of bacterial growth in $\mathrm{mm}$, total diameter $2\left(\mathrm{~d}_{2}\right)$ : both bacterial growth and pigment inhibition in $\mathrm{mm}$ (Ilk et al., 2017). The assay was performed in three independent experiments.

\section{Quantitative Evaluation of Violacein Inhibition}

Quantitative evaluation of QSI activity of the strawberry phenolic extracts was determined to inhibit the purple pigment 'violacein' production by $C$. violaceum ATCC 12472. The inhibition of violacein production by C. violaceum ATCC 12472, when exposed to strawberry phenolic extract, was quantified according to described method with slight modifications (Ilk et al., 2017). The $C$. violaceum ATCC12472 suspension was adjusted to an $\mathrm{OD}_{620} \mathrm{~nm}$ of 0.1 and different concentrations of phenolic extract $\left(0.5,0.25,0.1,0.05 \mathrm{mg} \mathrm{mL}^{-1}\right)$ were added to the bacterial suspension. The ethanol $(5 \%, \mathrm{v} / \mathrm{v})$ was used as a control. After the incubation $\left(24 \mathrm{~h}, 30^{\circ} \mathrm{C}, 150 \mathrm{rpm}\right)$, the violacein extraction was carried out. Briefly, to precipitate the insoluble violacein and bacterial cells, each culture of samples was centrifuged (11000 rpm, $10 \mathrm{~min})$. Then, the pellet was solubilized in ethanol/water $(1 \mathrm{~mL})$, vortexed for $1 \mathrm{~min}$ to solubilize the violacein and centrifuged again (10000 rpm, $10 \mathrm{~min}$ ). Finally, the absorbance at $585 \mathrm{~nm}$ of the obtained supernatant within the violacein pigment was measured by UV/Vis spectrophotometer. These experiments were performed in triplicate. The results were presented as percentage of violacein inhibition (VI\%) and calculated by using the following formula:

$$
\mathrm{VI} \%=\left(\left(\mathrm{Abs}_{\text {control }}-\mathrm{Abs} \text { test }\right) / \mathrm{Abs}_{\text {control }}\right) \times 100
$$

\section{Results and Discussion}

Phenolic content and antioxidant activity

Strawberry phenolic extract was exhibited at high amount of total phenolics and antioxidant capacity for both ABTS and FRAP methods tested (Table 1). Total

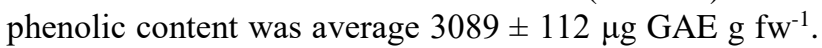
Antioxidant capacities were $28.4 \pm 0.3$ and $26.2 \pm 0.5$ mmol TE $\mathrm{L}^{-1}$ for both ABTS and FRAP methods, respectively. Results obtained from this study were compatible with previous strawberry studies (Özgen et al., 2007) conducted by different commercial strawberry cultivars. The average values of phenolic content and antioxidant capacity of mature strawberry fruits obtained from four different cultivars were $2639 \mu \mathrm{g} \mathrm{GAE} \mathrm{g} \mathrm{fw}^{-1}$ and $22.0 \mathrm{mmol} \mathrm{TE} \mathrm{L}^{-1}$, respectively.

Table 1 Total phenolic content and antioxidant activity of strawberry fruits (Fragaria $\times$ ananassa cv. 'Rubygem') phenolic extracts

\begin{tabular}{|c|c|c|}
\hline Total Phenolic Content & \multicolumn{2}{|c|}{ Antioxidant Capacity } \\
\hline $\begin{array}{l}\text { Folin-Ciocalteu Assay } \\
\left(\mu \mathrm{g} \mathrm{GAE} \mathrm{g} \mathrm{fw}^{-1}\right) \\
3089 \pm 112\end{array}$ & $\begin{array}{c}\text { ABTS Assay } \\
\left(\mathrm{mmol} \mathrm{TE} \mathrm{L}^{-1}\right) \\
28.4 \pm 0.3\end{array}$ & $\begin{array}{c}\text { FRAP Assay } \\
\left(\mathrm{mmol} \mathrm{TE} \mathrm{L}^{-1}\right) \\
26.2 \pm 0.5\end{array}$ \\
\hline
\end{tabular}

Antimicrobial Activity

The fruit phenolic extracts and compounds have gained attention and have been investigated especially in in vitro systems in recent decades. The antibacterial activity of strawberry phenolic extracts was studied on six 
strains of gram-positive and negative bacteria by using the disc diffusion method, because it is cheap, simple and has practical assay (Bachir and Benali, 2012). The results for the disc diffusion assay with the strawberry phenolic extracts at different concentrations against human pathogens gram negative bacteria $E$. coli ATCC 25922, $P$. vulgaris ATCC 6380, Salmonella spp. and the gram positive bacteria $S$. aureus ATCC 25923, S. mutans ATCC 25175 and B. subtilis ATCC 21332, are shown in Figure 2 and 3. As presented in Figure 2, the strawberry phenolic extract at least at three concentrations inhibited all the tested gram negative bacteria. The most sensitive bacterium in gram negative bacteria was Salmonella spp. that was inhibited in all evaluated concentrations and demonstrated as the highest zone of inhibition (16.56 \pm $0.42 \mathrm{~mm}$ ) (Figure $2 \mathrm{E}-\mathrm{F}$ ). The antimicrobial activity of phenolic extracts against gram positive bacteria is shown in Figure 3. The phenolic strawberry extract exhibited antibacterial activity all the evaluated gram positive bacteria, at least at three concentrations. The most sensitive bacterium in gram positive bacteria was $S$. mutans ATCC 25175 which was inhibited in all evaluated concentrations of extract and showed the highest zone of inhibition $(17.12 \pm 0.45 \mathrm{~mm})$. The results were presented in Figure 2 and 3 and it was possible to conclude that strawberry phenolic extract was more effective inhibitor against the gram positive microorganisms, while the inhibition zones' diameters were greater than the gram negatives. In addition, in all tested bacteria, it was observed that with increasing concentration of phenolic extract increased the zone of inhibition. Once again, no studies were found for the antimicrobial activity of strawberry fruit extracts. The studied phenolic extract can act as potential improving agents of antibiotics against gram positive and negative bacteria, considering the synergic effect obtained between these phenolic extract and conventional antibiotics.

\section{Quorum sensing inhibition in C. violaceum (Plate diffusion assay)}

In this study, the anti-QS activity of strawberry phenolic extracts was evaluated using the biomonitor strain C. violaceum ATCC12472. This biomonitor strain is a gram negative bacterium and produces the 'violacein' purple pigment for the bacterial communication system (QS) which is regulated by C6-AHL (Tan et al., 2012). Therefore, this may be excellent strain for screening of the QSI properties of compounds (Adonizio et al., 2006). When the results of the disc diffusion assay concerned to screen of the QSI activity of phenolic compounds (Figure 4), it was verified that strawberry phenolic extracts inhibited the violacein production by $C$. violaceum ATCC 12472. The inhibition of violacein production was seen by the turbid halo formation on a clear background around the disc. The strawberry phenolic extract inhibited the violacein production (Figure 4A) that demonstrates bacterial growth can be observed but no color production by the turbidity of the halo formation. The obtained results from the assay of disc diffusion were more promising than the results of other studies (Khan et al., 2009; Singh et al., 2009 and Del Monte et al., 2015). The QSI properties of the strawberry phenolic extracts at different concentrations were also evaluated (Figure 4B).
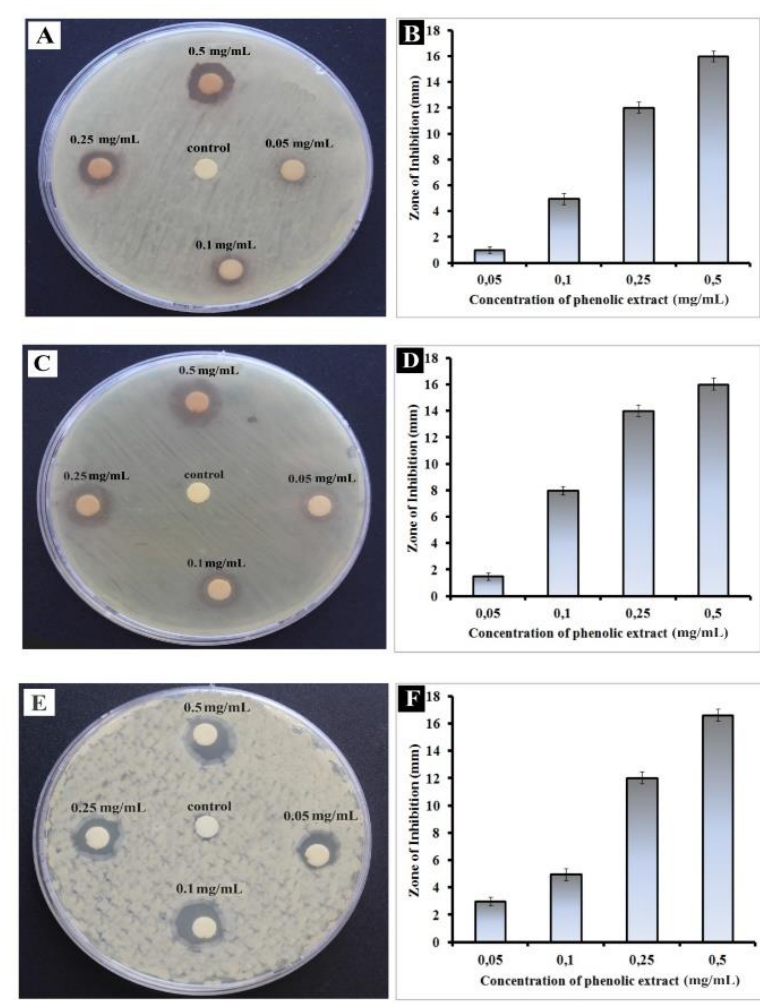

Figure 2 Growth inhibition against Gram negative bacteria E. coli (A and B), P. vulgaris (C and D), Salmonella spp. (E and F) by different concentrations of strawberry (Fragaria $\times$ ananassa cv. 'Rubygem') phenolic extract, measured as inhibition zone around the discs $(\mathrm{mm})$, by the plate diffusion assay
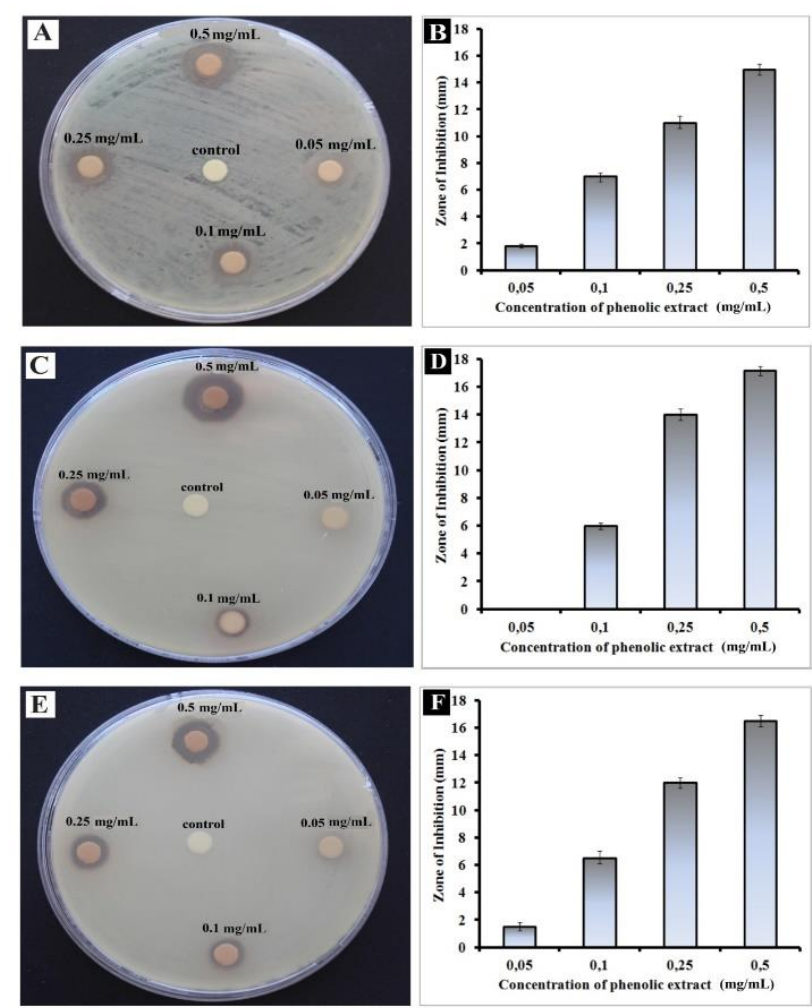

Figure 3 Growth inhibition against Gram positive bacteria S. aureus (A and B), S. mutans (C and D), B. subtilis (E and $\mathrm{F}$ ) by different concentrations of strawberry

(Fragaria $\times$ ananassa $\mathrm{cv}$. 'Rubygem') phenolic extract measured as inhibition zone around the discs $(\mathrm{mm})$, by the plate diffusion assay 

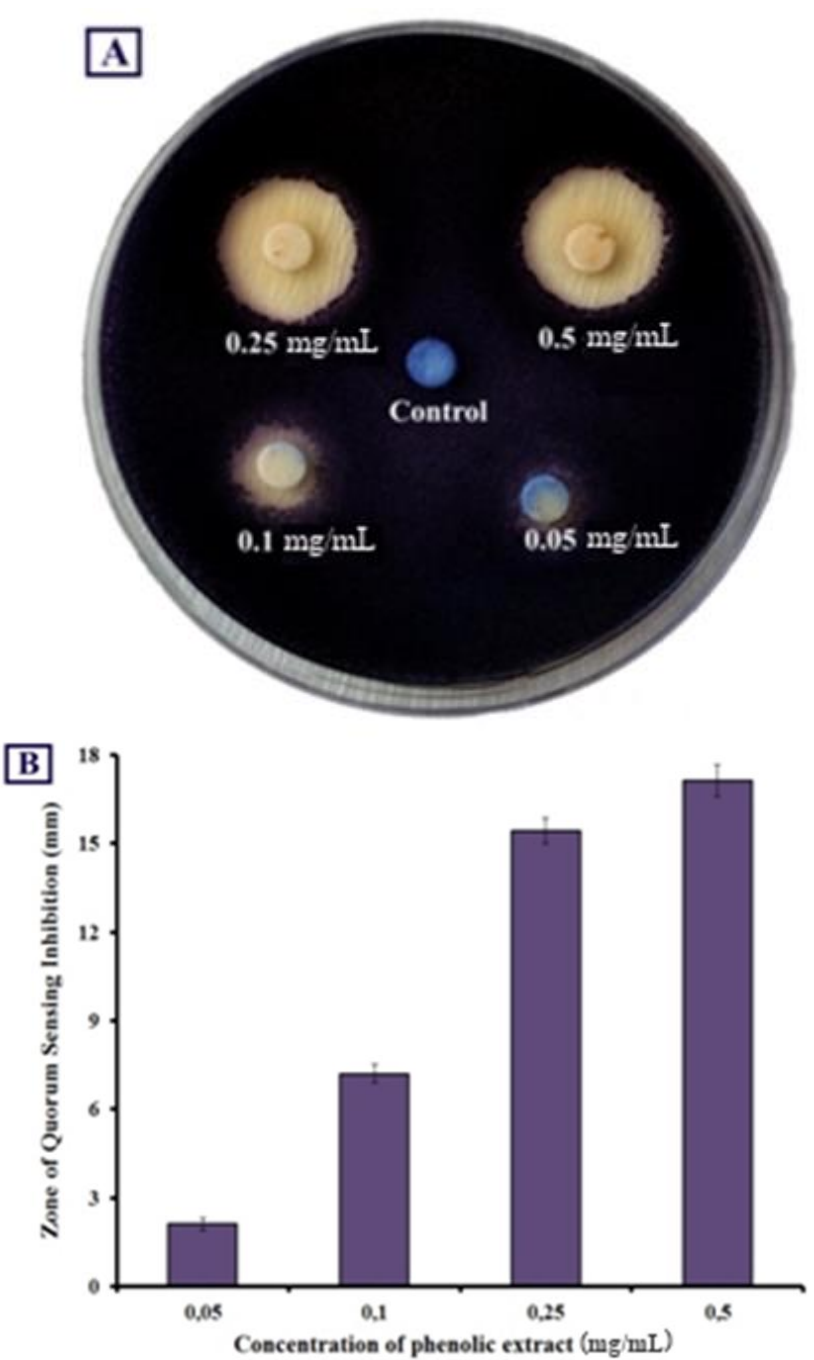

Figure 4 Plate diffusion assay for the quorum sensing inhibition in $C$. violaceum by different concentrations of strawberry (Fragaria $\times$ ananassa cv. 'Rubygem') phenolic extract (A) Dual plate assay (B) Quorum sensing inhibition zone (mm)

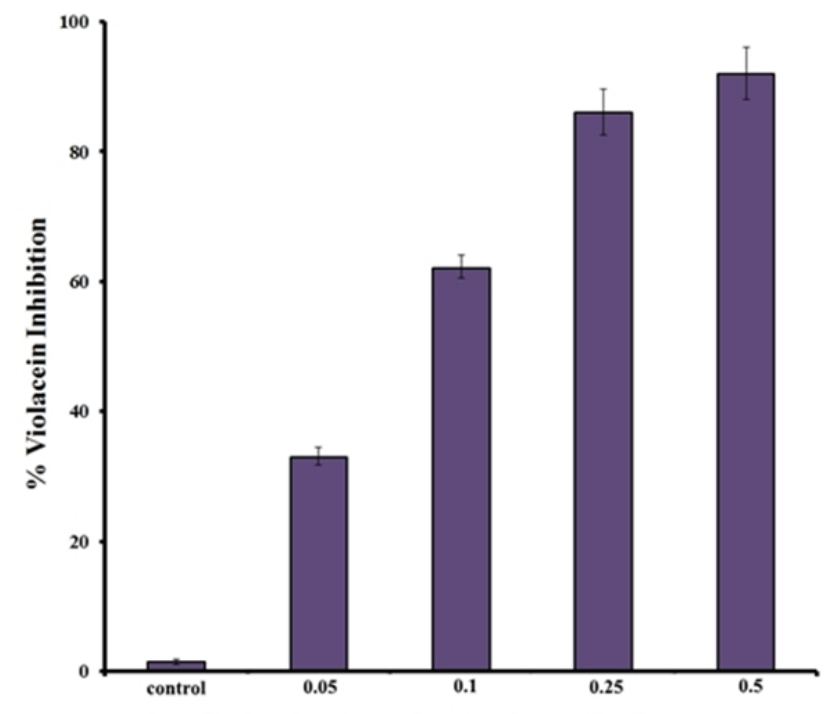

Concentration of phenolic extract $(\mathrm{mg} / \mathrm{mL})$

Figure 5 Percent inhibition of violacein production by the strawberry (Fragaria $\times$ ananassa cv. 'Rubygem') phenolic extract at different concentrations. The control consisted of LB medium added of $200 \mu \mathrm{L}$ of ethanol:water $(5: 95)$
Violacein production was inhibited at all the sample concentrations tested. There was not any inhibition on violacein production in the control. These results were confirmed with QSI capacity of the strawberry phenolic extract which was able to inhibit the violacein production in a concentration dependent manner. The inhibition of QS by other natural extracts was reported with the same findings in other studies (Ilk et al., 2017; Singh et al., 2009; Abraham et al., 2012). Overall, strawberry phenolic extract can inhibit the QS-regulated violacein pigment production in bacteria without interrupting on their growth and this finding was reported first time with this study.

\section{Quantification of violacein inhibition of phenolic extract}

The strawberry phenolic extract was highly effective for the inhibition of the violacein production at all evaluated concentrations (Figure 5). The absorbance of viable cells evaluated after $24 \mathrm{~h}$ of incubation was indicated that there was inhibition at presence of phenolic extract against violacein production (Figure 5). The violacein inhibition by the phenolic extracts, especially at $0.5 \mathrm{mg} \mathrm{mL}-1$ was $92.6 \pm 4.2 \%$. No studies have been found on the effect of strawberry extract on the production of violacein. In general, the studies for finding new anti-pathogenic and QSI therapeutic compounds have been performed with plants, however studies showing the QSI effect of natural phenolic extracts are scarce (Adonizio et al., 2006; Abraham et al., 2011; Kalia, 2013).

\section{Conclusions}

In this study, we reported the bioactive potential (antioxidant, antimicrobial and anti-quorum sensing activities) of strawberry fruits cv. 'Rubygem' with the presence of phenolic compounds. The significant inhibition of the quorum-sensing regulated pigment production against the bacteria $C$. violaceum $\mathrm{CV} 026$ was observed in the first time using only the phenolic extract of strawberry without the addition of any toxic and synthetic chemical agents. Moreover, the bacterial growth was significantly interfered by the phenolic content of strawberry. Although the exact mechanism for observing strong anti-QS effect of the phenolic compounds is still to be unraveled, it is believed to be related to the flavonoids contents of the phenolics such as kaempferol and quercetin in the antioxidant rich strawberry. Since the autoinducer for the pigment production of $C$. violaceum CV026 also regulates many other important physiological processes of bacteria, it is expected that our natural strawberry freeze dried powder can be potentially used to inhibit those physiological processes including biofilm formation. Strawberry may be a good source for new bioactive agents with QSI activity which could be further discovered as a means to produce new additives and antivirulence drugs for the several industrial applications.

\section{References}

Abraham SVP, Palani A, Ramaswamy BR, Shunmugiah KP, Arumugam VR. 2011. Antiquorum sensing and antibiofilm potential of Capparis spinosa. Archives of Medical Research 42: 658-668. doi: 10.1016/j.arcmed.2011.12.002 
Adonizio A, Kong K, Mathee K. 2006. Anti-quorum sensing activity of medicinal plants in southern Florida. Journal of Ethnopharmacology 105: 427-435. https://doi.org/10.1016/ j.jep.2005.11.025

Andersson DI, Hughes D. 2010. Antibiotic resistance and its cost: is it possible to reverse resistance? Nature Reviews Microbiology 8: 260-271. doi:10.1038/nrmicro2319

Andrade BF, Nunes Barbosa L, da Silva Probst I, Fernandes Júnior A. 2014. Antimicrobial activity of essential oils. Journal of Essential Oil Research 26: 34-40. https://doi.org/10.1080/10412905.2013.860409

Bachir RG, Benali M. 2012. Antibacterial activity of the essential oils from the leaves of Eucalyptus globulus against Escherichia coli and Staphylococcus aureus. Asian Pacific Journal of Tropical Biomedicine 2: 739-742. doi:10.1016/ S2221-1691(12)60220-2

Benzie IFF, Strain JJ. 1996. The ferric reducing ability of plasma (FRAP) as a measure of "antioxidant power": The FRAP assay. Analytical Biochemistry 239: 70-76. https://doi.org/10.1006/abio.1996.0292

Borges A, Serra S, Abreu AC, Saavedra MJ, Salgado A, Simões M. 2013. Evaluation of the effects of selected phytochemicals on quorum sensing inhibition and in vitro cytotoxicity. Biofouling: The Journal of Bioadhesion and Biofilm Research 30(2): 183-195. doi: 10.1080/ 08927014.2013.852542

Campbell T, Bowen-Forbes C, Albersberg W. 2015. Phytochemistry and biological activity of extracts of the red raspberry Rubus rosifolius. International Journal of Nutritional Food Science 2 (3).

Cowan MM. 1999. Plant products as antimicrobial agents. Clinical Microbiology Review 12 (4): 564-582.

Del Monte D, De Martino L, Marandino A, Fratianni F, Nazzaro F, De Feo V. 2015. Phenolic content, antimicrobial and antioxidant activities of Hypericum perfoliatum L. Industrial Crops and Products 74: 342-347. https://doi.org/ 10.1016/j.indcrop.2015.04.036

Hentzer M, Givskov M. 2003. Pharmacological inhibition of quorum sensing for the treatment of chronic bacterial infections. The Journal of Clinical Investigation 112: 13001307. doi:10.1172/JCI200320074

Herrington Mark E, Chandler Craig K, Moisander Jennifer A, Reid Claire E. 2007. 'Rubygem' Strawberry. HortScience 42: $1482-1483$.

Ilk S, Sağlam N, Özgen M, Korkusuz F. 2017. Chitosan nanoparticles enhances the anti-quorum sensing activity of kaempferol. International Journal of Biological Macromolecules 94: 653-662. doi:10.1016/ j.ijbiomac.2016.10.068

Jorge P, Lourenço A, Pereira MO. 2012. New trends in peptidebased anti-biofilm strategies: A review of recent achievements and bioinformatic approaches. Biofouling 28: 1033-1061. doi: 10.1080/08927014.2012.728210

Kalia VC. 2013. Quorum sensing inhibitors: an overview. Biotechnology Advances 31: 224-245. doi: 10.1016/ j.biotechadv.2012.10.004

Khan MSA, Zahin M, Hasan S, Husain FM, Ahmad I. 2009. Inhibition of quorum sensing regulated bacterial functions by plant essential oils with special reference to clove oil. Letters in Applied Microbiology 49: 354-360. doi:10.1111 /j.1472-765X.2009.02666.x

Martins N, Barros L, Henriques M, Silva S, Ferreira ICFR. 2015. Activity of phenolic compounds from plant origin against Candida species. Industrial Crops and Products 74: 648-670. doi:https://doi.org/10.1016/j.indcrop.2015.05.067
McCarthy RR, O'Gara F. 2015. The impact of phytochemicals present in the diet on microbial signalling in the human gut. Journal of Functional Foods 14: 684-691. doi: https://doi.org/10.1016/j.jff.2015.02.032

O'Loughlin CT, Miller LC, Siryaporn A, Drescher K, Semmelhack MF, Bassler BL. 2013. A quorum-sensing inhibitor blocks Pseudomonas aeruginosa virulence and biofilm formation. Proceedings of the National Academiy of Sciences USA 110: 17981-17986. doi: 10.1073/pnas. 1316981110

Özgen M, Reese RN, Tulio AZ, Miller AR, Scheerens JC. 2006. Modified 2,2-Azino-bis-3-ethylbenzothiazoline-6-sulfonic Acid (ABTS) Method to Measure Antioxidant Capacity of Selected Small Fruits and Comparison to Ferric Reducing Antioxidant Power (FRAP) and 2,2'-Diphenyl-1picrylhydrazyl (DPPH) Methods. Journal of Agricultural Food and Chemistry 54: 1151-1157. doi: 10.1021/jf051960d

Özgen M, Serçe S, Gunduz K, Yen F, Kafkas E, Paydas S. 2007. Determining total phenolics and antioxidant capacities of selected Fragaria genotypes. Asian Journal of Chemistry 19: 5573-5581.

Pinho E, Ferreira ICFR, Barros L, Carvalho AM, Soares G, Henriques M. 2014. Antibacterial potential of northeastern Portugal wild plant extracts and respective phenolic compounds. Biomedical Research International 2014:1-8. doi: http://dx.doi.org/10.1155/2014/814590

Projan SJ, Youngman PJ. 2002. Antimicrobials: new solutions badly needed. Current Opinion in Microbioogy 5: 463-465. doi: https://doi.org/10.1016/S1369-5274(02)00364-8

Puupponen-Pimia R, Nohynek L, Alakomi HL, OksmanCaldentey KM. 2005. Bioactive berry compounds-novel tools against human pathogens. Applied Microbiology and Biotechnology 67: 8-18. doi: 10.1007/s00253-004-1817-x

Santoni A, Amanda H, Darwis D. 2015. Characterization of pelargonid in compound from raspberry fruit (Rubus rosifolius $\mathrm{Sm}$ ) with mass spectroscopy method. Journal of Chemical and Pharmaceutical Research 7: 804-808.

Singh BN, Singh BR, Singh RL, Prakash D, Sarma BK, Singh HB. 2009. Antioxidant and anti-quorum sensing activities of green pod of Acacia nilotica L. Food Chemistry and Toxicology 47: 778-786.

Singh BN, Singh HB, Singh A, Singh BR, Mishra A and Nautiyal CS. 2012. Lagerstroemia speciosa fruit extract modulates quorum sensing-controlled virulence factor production and biofilm formation in Pseudomonas aeruginosa. Microbiology 158: 529-538. doi:10.1099 /mic.0.052985-0

Singleton VL, Rossi JA. 1965. Colorimetry of total phenolics with phosphomolybdic phosphotungstic acid reagents. The American Journal of Enology and Viticulture 16: 144-158.

Tan LY, Yin WF, Chan KG. 2012. Silencing quorum sensing through extracts of Melicope lunuankenda. Sensors 12: 4339-4351. doi: 10.3390/s120404339

Tiveron AP, Melo PS, Bergamaschi KB, Vieira TM, Gegitano M, -d'1Arce MA, Alencar SM. 2012. Antioxidant activity of Brazilian vegetables and its relation with phenolic composition. International Journal of Molecular Science 13: 8943-8957. doi: 10.3390/ijms13078943

Yağız F, Battaloğlu R, İlk S, Savran A. 2017. Antibacterial Activity and Chemical Composition of Essential Oils from Some Galium (Rubiaceae) Species Against Pathogenic Bacteria. Turkish Journal of Agriculture - Food Science and Technology 5(11): 1330-1333. doi: https://doi.org/ 10.24925/turjaf.v5i11.1330-1333.1414 